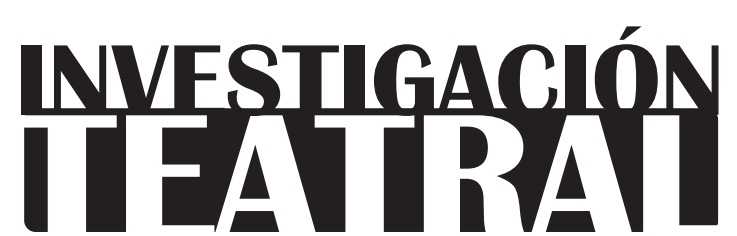

Revista de artes escénicas y performatividad

Vol. 11, Núm. 17

abril-septiembre 2020

Segunda época

ISSN impreso: 1665-8728

ISSN electrónico: 2594-0953

Universidad Veracruzana

\title{
Documento:
}

\section{Una escena con múltiples entradas. Entrevista con Miguel Rubio Zapata}

\author{
Ana Carolina Fialho de Abreu* \\ Paola Lopes Zamariola**
}
* Universidade Federal da Bahia, Brasil. e-mail: anacarolinaabreu1886@gmail.com
** Universidade de São Paulo, Brasil.
e-mail:paola.lopes.zamariola@gmail.com

Recibido: 01 de noviembre de 2019

Aceptado: 19 de marzo de 2020

Doi: $10.25009 /$ it.v11i17.2631 


\section{Una escena con múltiples entradas. Entrevista con Miguel Rubio Zapata}

\section{Presentación}

$\mathrm{M}$ iguel Rubio Zapata es director y miembro fundador del Grupo Cultural Yuyachkani, ${ }^{1}$ además de investigador de teatro latinoamericano. Junto con los integrantes de Yuyachkani, el maestro Rubio postula un teatro de creación e investigación a partir del material que los actores y las actrices producen, siempre en relación con la cultura, la sociedad y la situación política del Perú. Es egresado de la Facultad de Ciencias Sociales de la Especialidad de Sociología de la Universidad Particular Inca Garcilaso de la Vega (1974), su experiencia tiene como base la investigación de la cultura peruana y su aplicación en las expresiones artísticas contemporáneas. Ha sido director de múltiples obras teatrales y creaciones colectivas, tales como: Puño de cobre (1972), Los músicos ambulantes (1983), Antígona (2000), Santiago (2000), Sin título: técnica mixta (2004), Con-cierto olvido (2010), Cartas de Chimbote (2015) y Discurso de promoción (2017). En 2010, la Universidad de La Habana ISA (Cuba) le otorgó el doctorado honoris causa en Arte. En 2019 fue galardonado en su país natal con el Premio Nacional de Cultura, en la categoría "Trayectoria”. Ha publicado los libros Notas sobre teatro (2000), El

1 Yuyachkani -palabra quechua que significa "estoy pensando", "estoy recordando"- es un grupo cultural reconocido como uno de los máximos exponentes del teatro peruano y latinoamericano. Creado en 1971, el colectivo recorre caminos de búsqueda sustentados en la investigación del comportamiento escénico del actor desde la perspectiva de una cultura de grupo: en ésta concurren fuentes diversas, tradicionales y contemporáneas, cuyos trabajos son resultado de procesos a partir de los materiales que se generan en el espacio. 
INVESTIGACIONTEATRAL

Revista de artes escénicas y performatividad

Vol. 11, Núm. 17

abril-septiembre 2020
Una escena con múltiples entradas. Entrevista con Miguel Rubio Zapata

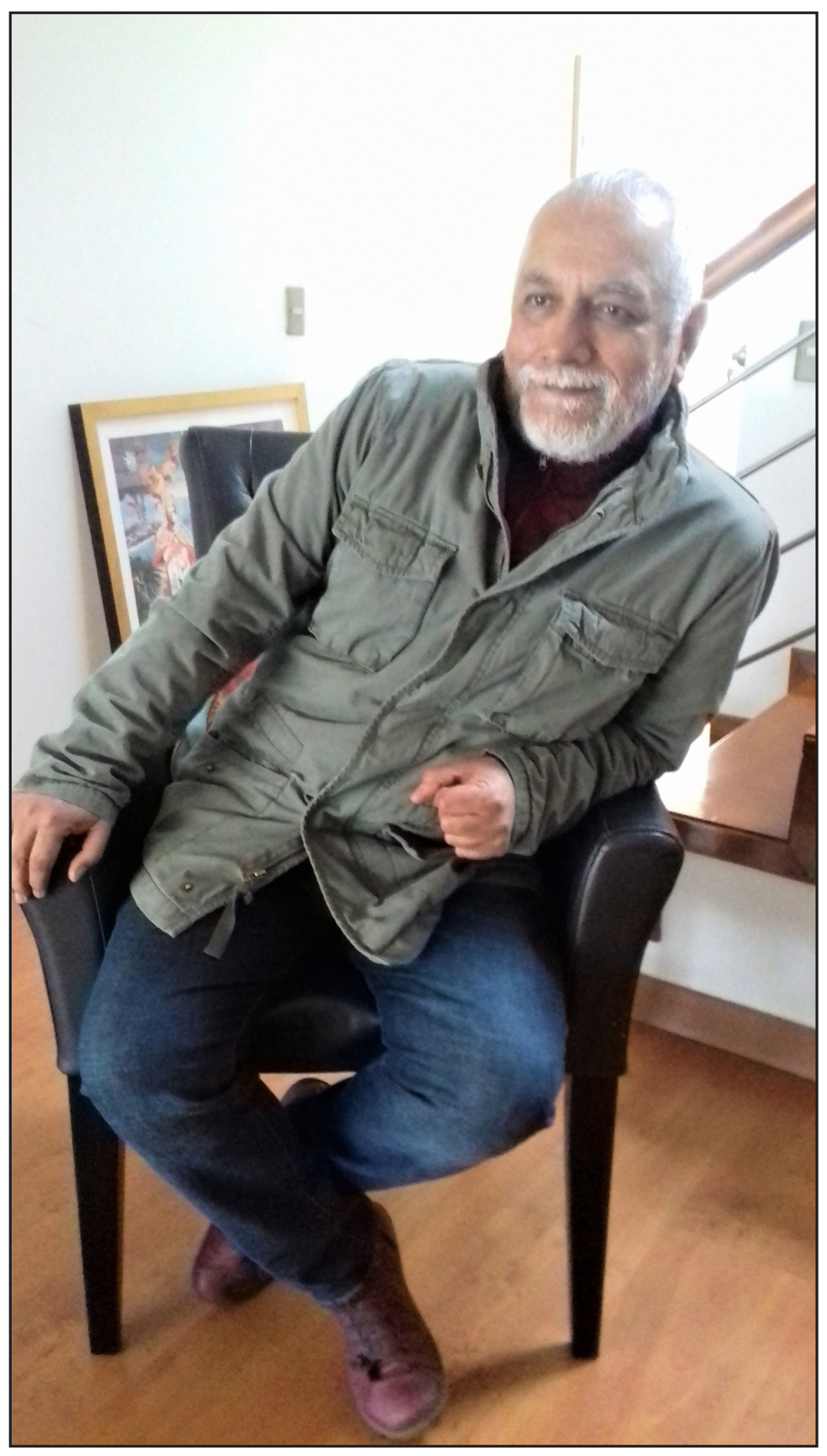

Ana Carolina Fialho, Paola Lopes
Miguel Rubio Zapata.

Lima, Perú, 2018. Fotografía de Ana Carolina Abreu. 
cuerpo ausente (performance política) (2008), Raíces y semillas. Maestros y caminos del teatro en América Latina (2011) y Guerrilla en Paucartambo (2013), entre otras.

La siguiente entrevista fue realizada en julio de 2018, en el contexto de las festividades a la Virgen del Carmen, en la ciudad de Paucartambo, Perú. El maestro Rubio compartió sus experiencias a lo largo de los últimos 48 años, así como las formas como Yuyachkani ha transformado su corporalidad escénica en respuesta al cambiante contexto social y político.

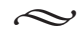

\section{PL: ¿Cómo llegaste a la fiesta de Paucartambo?}

MR: Yo creo que eso tiene que ver con las primeras veces que Yuyachkani salió fuera de Lima. Ya en algún momento les he contado que, en los años 70, cuando empezamos la primera obra [Puño de cobre], nos comprometimos con un grupo de obreros mineros en lucha. Entonces, nuestra manera de devolver lo que habíamos recibido de ellos era hacer la obra, pero no sabíamos cómo hacerlo. Éramos muy jóvenes. Fue así que salimos de Lima por primera vez y ahí nos encontramos con ese mundo de la máscara, del vestido y de la danza. Fue en el año 73. Y eso sirvió para preguntarnos: "¿y qué tiene que ver esa máscara con el teatro?", pero eran preguntas aún muy incipientes. Yo también era actor y estaba muy fascinado por la teoría de Boal, el método del coringa. ${ }^{2}$ Entonces, nuestra obra estaba entre el teatro documento y Boal. Yo cuento en un libro que, al final de la obra, un obrero me dice: "que linda su obra, pero una pena que se olvidaran de sus disfraces", y obviamente eso lo cuento siempre como anécdota, porque ese fue un punto de quiebre importante para nosotros, ya que llevamos una idea de teatro sin referentes y memoria, y nos encontramos con niveles de representaciones magníficos. Y de ahí comenzó a quedarse con nosotros esa inquietud por el uso del espacio, por la máscara, por la danza, por el tipo de actor que necesitaríamos.

Ahora podemos hablar de un actor danzante y lo vinculo con la teatralidad asiática, ya que considero que esa realidad se parece mucho más a la nuestra, a la América originaria, sobre todo. Desde ahí nos pareció imposible la separación entre cabeza y cuerpo. En el teatro hegemónico muchas veces tú puedes decidir tu personaje desde el libreto, y no me gusta el término "puesta en escena", porque la idea de poner en escena sugiere que en el teatro existe un lugar y lo pone en escena, o sea, lo cambia de lugar y yo creo que el tea-

2 N. del Ed. El método coringa, desarrollado por Augusto Boal, consiste en flexibilizar la representación de piezas teatrales con elencos reducidos, de tal forma que un actor puede representar diversos personajes, y cada escena pueden tener su propio género y estilo. 
tro es una escritura que se da en el espacio, que se crea ahí y ése es un momento efímero, nada más, que tiene principio y final. Paucartambo concentra unos niveles de teatralidad donde están presentes lo simbólico, lo relacional, lo espacial, el tema de la improvisación, lo narrativo. El teatro es todo esto. Y en la fiesta de Paucartambo están presentes todos estos elementos de teatralidad. El espacio mismo es un espacio indispensable, son sitios específicos. El cementerio tiene que ser en un cementerio, la central de las danzas tiene que ser por determinadas calles, o sea, la geografía del pueblo, que es el gran escenario de la representación, ya que te alude a la memoria, a las historias y a las narrativas que traen esos espacios, donde las 19 danzas son importantes.

Considero que esa es la tarea ahora: pensar en esos términos, pensar en términos de teatralidad andina - todavía hay que preguntarse qué cosa es lo andino y qué cosa es la teatralidad-, pero, antes de eso, yo creo que hay una base que es el ayni, la práctica de reciprocidad, de intercambio y de reconocimiento con el otro. En algunos sectores urbanos, el ayni se entiende como el "dar para recibir"; sin embargo, no es un trueque inmediato, tú das lo que tienes y lo que puedes, sin esperar a cambio algo muy específico; tú entregas a tu comunidad y la devolución te llegará en algún momento. En estas relaciones de intercambio de ayni -que es con el cosmos, la tierra, las plantas, los animales, la gente, los frutos, los muertos, los niños, con todo lo que tiene vida- se dan esas prácticas que no tienen por finalidad hacer teatro, sino que tienen características simbólicas de representación que se parecen a lo que nosotros llamamos teatro.

¿Cuáles son las relaciones, entonces? Creo que ahí es donde debemos encontrar cuáles son esos puentes que me llevan a conceptos de "origen" prehispánico, como por ejemplo pukllay, que en quechua es "jugar", y en muchos idiomas se define al teatro como juego, o la palabra taki que es "cantar y bailar". El taki más conocido es el Taki Onqoy, que es posiblemente la fuente de la Danza de Tijeras. A mí me da mucha rabia que nosotros vivamos sometidos a un concepto de teatro pensado desde que los núcleos dramáticos de origen quechua fueron formateados a la manera hispana. Lo más conocido es el Ollantay. ${ }^{3}$

Entonces, ¿cómo releemos esto que no tiene un texto previo, pero que son relaciones, prácticas, reciprocidades de juego, intercambio y enmascaramiento? Eso es lo que nos queda por estudiar, analizar y mirar con ojos de esa particularidad. Creo que esa va a ser una tarea colectiva en la que ustedes también tienen, por supuesto, un rol, tienen que devolver a la $M a-$ macha Carmen, ${ }^{4}$ pensando que hemos encontrado ahí en su fiesta [devolver en el sentido de agradecer, de tener, a partir de ese encuentro, un compromiso con la Virgen del Carmen].

3 N. del Ed. Ollantay es una obra dramática escrita durante la época colonial en lengua quechua.

4 En quechua se usa el sufijo "-cha" para formar el diminutivo ("mamacha" = mamacita). Mamacha Carmen es la forma cariñosa en que las personas devotas tratan a la Virgen. 


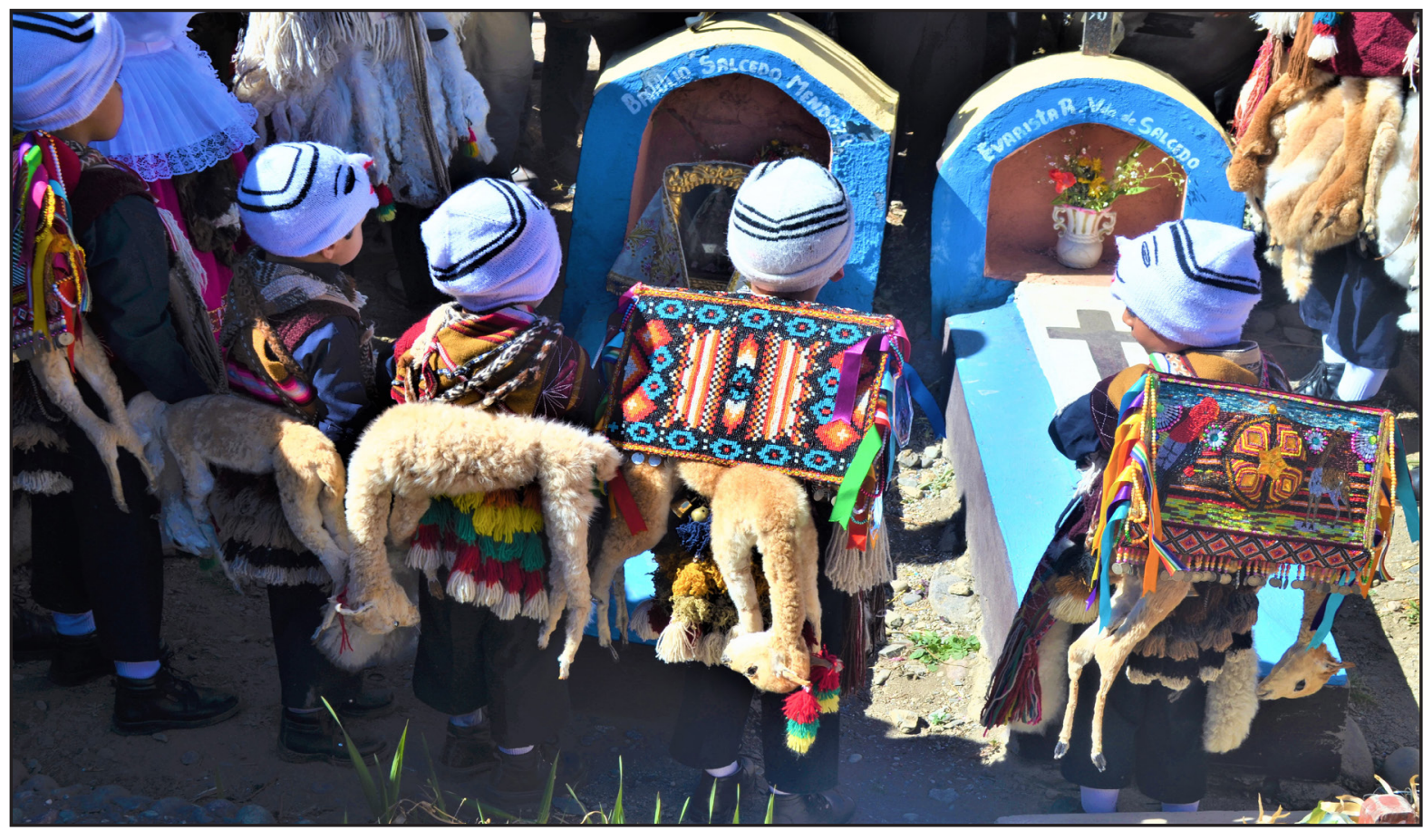

Fiesta en honor a la Virgen del Carmen en un cementerio. Paucartambo, Perú, 2018. Fotografía de Ana Carolina Abreu.

PL: Mirar por primera vez a Mamacha Carmen con todos los danzantes nos genera imágenes de fuentes muy distintas de un país. Ver la selva, lo andino, toda esa diversidad en acción...

MR: Y cómo esa diversidad negocia, ¿no? Porque toma a la plaza como espacio público y como una negociación política de esa diversidad. Cada danza representa sectores sociales, económicos, determinados barrios... tú lo ves en el vestido, en la máscara y cómo se negocia ese espacio en la plaza. Así, cada uno encuentra su lugar. Eso es hermoso y creo que es una gran metáfora de lo que necesitamos también como país, o sea, de reconocernos en esa diversidad. Muchas veces hablamos de lo diferente, que somos diferentes, eso lo sabemos, pero ¿cómo es ese intercambio de diferentes? Yo creo que esta guerrilla de Paucartambo es ese encuentro de diferentes, de funciones distintas en un todo armónico que parece una caja de un reloj que se abre y todo es simultáneo, pero articulado. Esos protagonistas se enfrentan y, al final, se abrazan en el Wataskama, pero no se abrazan los personajes, sino los actores danzantes ¡muy linda esa diferenciación! Después, ellos van afuera y acompañan a los qollas para que se vayan. Luego nos hemos ido a cenar con la Imilla (la esposa del Qapaq 
Qolla) en la misma mesa. Hemos estado con la Imilla y el Rey Ch'unchu, el guardaespaldas de la Imilla, la seguridad de la Imilla, cuidándola. Es muy interesante también pensar en términos políticos, en cómo políticamente eso nos habla de una manera de resolución de conflictos y de ritualizar la diferencia.

Siempre digo que, si yo tuviera que definir lo que entiendo por dramaturgia, diría que es la organización de la acción en el espacio compartido, organizar lo que sucede. Y esto significa pensar, por ejemplo, en la simultaneidad y el foco, como en tantos momentos simultáneos. Muchas de las obras que dirijo tienen esa simultaneidad y tienen también ese foco que va variando. Eso lo he aprendido también mirando a la fiesta. Pero, cuando miro, tengo que buscar equivalencias, los principios, lo que está abajo. No es robarme el personaje, robar la máscara y sacarla del contexto, sino ver lo que se conecta desde abajo, el uso del espacio, la convivencia con el espectador, ver cómo hay personajes que organizan la mirada del espectador. Claro que no necesitas ir a Paucartambo para pensar en eso, pero ratificar eso, de cómo nace ahí, en ese contexto, me parece que nos da como una temperatura cercana a una identidad nuestra. No es tomar del libro o de la escuela. Tú sientes que es una respuesta de la necesidad de la práctica, producto de la experiencia. Eso me parece interesante.

Como cuando fuimos a la fiesta con Julia Varley del Odin Teatret a mirar los techos y a los saqras (diablos) y me dice: "veo que el Odin no ha inventado nada", porque claro, obviamente, hay una conexión. Y Julia me dice: "qué buenos actores, qué grandes improvisadores, nunca he visto tantos actores juntos improvisando". Y es cierto. Esa práctica de improvisación, esa práctica relacional con el espectador, todo eso me permite repensar en términos de mi experiencia en el escenario y el tema de la dramaturgia, de cómo organizar la acción. También valorar la escritura en el cuerpo. Con cada danza, cada actor danzante tiene una otra escritura, no ha renunciado a la memoria que guarda el cuerpo. En el teatro, nosotros también trabajamos con fuentes de memoria para generar comportamientos, de la misma manera como ellos lo hacen. El tema de la fe en el actor danzante, el compromiso con su fe me parece importantísimo, el pagar para que eso suceda y la importancia para el espectador.

En los teatros, a veces, vemos que hay muchos grupos u obras desesperadas haciendo oferta dos por uno, van a la gente para que el público venga. En la fiesta de Paucartambo no se necesita llamar a nadie. La gente va porque necesita, surge esa necesidad de estar ahí para unos y para otros, para los espectadores y para los actores. Todos nos quedamos y necesitamos estar ahí.

También me pregunto por qué la gente tendría que ir a ver obras de Yuyachkani, de qué manera dialogo con mi espectador para que tenga esa misma necesidad que tiene el espectador que va a Paucartambo, de qué manera yo cultivo en mis compañeros esa necesidad por lo que estamos haciendo, para que tengan la necesidad de hacerlo, en un tiempo donde 
todo está embarcado por lo que funciona, por lo que te da dinero, por lo que está de moda, que son otros valores. Yo creo que la fiesta me remite a unos vínculos con el oficio que son bien fuertes. El uso del espacio también es uno de los más fundamentales, cómo ese cuerpo está inscripto: lo espacial, lo simbólico, lo relacional, las memorias del cuerpo, lo narrativo, también la improvisación. Finalmente, toda la fiesta es una gran narración, una obra de teatro que dura tres días, con sus noches.

\section{AF: Miguel, ¿se refleja eso aún más en las últimas obras de Yuyachkani?}

MR: Yo pienso que sí y también el vínculo con otras fiestas. Por ejemplo, el Corpus Christi es una fiesta muy importante. En la obra Sin título, técnica mixta hay imágenes de actores que se desplazan entre el público y dan testimonios. Para mí, son como los santos que quieren llegar a la catedral el día de la procesión del Corpus Christi, y ese uso del espacio, esa simultaneidad de la acción, yo creo que está tomada de esa fiesta. En las últimas obras, el tema del espectador como centralidad es fundamental; ahí el actor es quien tiene que negociar con el espectador, negociar los cuerpos en el espacio. Eso es un poco lo que sucede en Paucartambo, donde el espectador tiene la posibilidad de comprar sus asientos como en un teatro formal, pero también está el espectador que está abajo y tiene que negociar. Antes no había tribunas y todo era negociar los cuerpos en ese espacio compartido. Efectivamente, eso está más presente en las últimas obras, donde seguimos trabajando esta idea de organizar la acción del espacio.

Yo pienso que podríamos partir en dos la historia de la Yuyachkani: antes y después del conflicto armado. ${ }^{5}$ Pero los 20 años de conflicto también son una columna importante. $\mathrm{Si}$ tú ves el cuerpo, las dramaturgias, las ideas sobre todo el cuerpo en los primeros 10 años de Yuyachkani y los ves en los últimos años, notarás que no solamente nos hemos hecho más viejos, sino también hay una postura distinta del cuerpo. Durante los primeros años vivíamos el cuerpo heroico, de puño cerrado y firme; esa inspiración de la Ópera de Pekín, del destacamento rojo de mujeres, de la revolución triunfante, del Che, digamos del impulso que dio en América Latina la revolución cubana, y cómo eso generó un cambio cultural en la renovación del Cinema Novo, en los grupos musicales. Todo lo que pasó en América Latina se reflejó también en una calidad de energía, en un tiempo y una temática, en una manera de decirle al espectador que la revolución estaba muy pronta; o sea, que había que arreglarlo todo para eso. De pronto, llegó el conflicto armado, lo interesante es que Yuyachkani no dejó de hacer trabajo [en ese contexto violento].

5 N. del Ed. Perú pasó por un largo periodo de conflicto armado - entre 1980 y 2000- a causa de la violenta lucha entre grupos subversivos como Sendero Luminoso y fuerzas tanto militares como paramilitares del gobierno, lo que resultó en la muerte de más de 50,000 personas. 
Seguimos ahí en la casa y esta situación nos planteó muchos retos. Nos reconocimos más en nuestra condición urbana, ya que no podíamos salir de Lima y menos al interior, porque éramos sujetos de sospecha, de un lado o de otro. Fuimos sujetos de sospecha, porque nunca abandonamos una postura crítica y de diálogo con los temas de Perú. Quedarnos significó pensar en un cuerpo más urbano, en tener una dramaturgia más subjetiva, el viaje al interior del individuo, el cambio de paradigma y generar, en esa construcción de subjetividad, otra relación con el espectador. Ya no es decirle al espectador "esto es así", sino preguntarle: “qué hacemos?”.

Se tornó un tiempo más bien de preguntas, de confesión y de pensar en qué lugar estás. Cuando ese periodo termina, comienza el de la Comisión de la Verdad y la Reconciliación. Estoy hablando del año 2001, y la Comisión de la Verdad nos pide que hagamos un acompañamiento a las audiencias públicas. Las audiencias públicas son reuniones en los lugares donde han habido conflictos para recoger testimonios de las víctimas directamente afectadas. Fue un momento de crisis tremendo, porque nosotros nos preguntamos: ¿Qué tenemos que decir frente a eso? ¿A quién vamos representar? ¿Qué tenemos que decirle a los afectados? Ahí se produjo lo que llamo la crisis de la representación en Yuyachkani, donde empieza ese tema de decir: “¿Qué hacemos? ¿Cómo hacemos? ¿En qué lugar estamos?". Este momento fue muy interesante, porque nos cuestionó, nos obligó a pensar en otras maneras de hacer propuestas, digamos, performativas, acciones que llamen la atención en los sitios para enfocar la atención en el testimonio. Por ello, pienso que la obra Sin título: técnica mixta [del 2004] fue la expresión de esta crisis, como decir: "vamos a poner toda nuestra documentación, nuestro cuerpo no tiene nada qué representar, nuestro cuerpo es un cuerpo que solamente debe servir como soporte de información". Fui con esa consciencia a la sala de ensayos y mis compañeros estaban muy asombrados, porque yo les decía: “Qué relación mentirosa!”, “No quiero que representen”, “Escribe en tu ropa”. Entonces, un día me dicen: "Bueno, hace tantos años que nosotros tenemos una cultura de actor y hemos pasado por diferentes culturas del cuerpo y ¿tú nos pides ahora que neguemos todo eso? ¿Cómo es eso?”. Creo que eso fue interesante, porque la obra sólo se llamaba Sin título y después de ese momento se llama: Sin título: técnica mixta, porque incorpora este reclamo de los actores. Así surge esa obra que está en el marco, en el paradigma de los derechos humanos; su universo teórico, su discurso central, está hecho en el discurso que realizara de Salomón Lerner, presidente de la Comisión de la Verdad y Reconciliación (CVR), luego de la entrega el Informe Final de la CVR. Esta obra se enmarca en los derechos humanos, porque éramos casi como un grupo inscrito a la CVR.

Después, tuvimos la intención de hacer una segunda versión llamada: Sin título II, como una segunda parte, pero también pensé que ya nuestra mirada había cambiado. Pensába- 


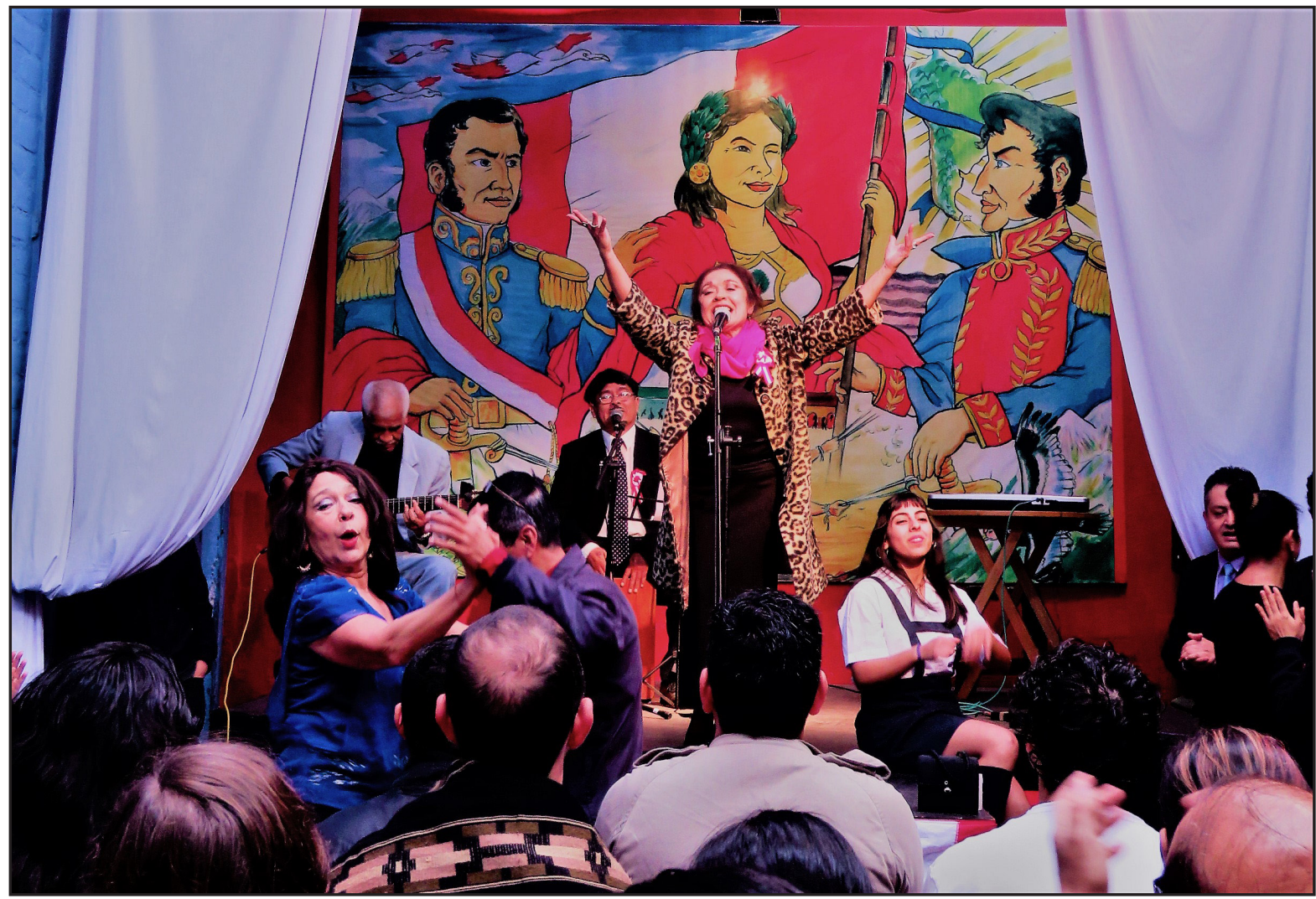

Las actrices Teresa Ralli (izquierda) y Rebeca Ralli (al centro) junto con colaboradores del grupo Yuyachkani en la escena inicial de la obra Discurso de promoción, presentada en el patio de la Casa Yuyachkani en Lima, Perú, 2018. Fotografía de Claudia V. Figueroa.

mos que había que salir del paradigma de los derechos humanos y mirar políticamente ese tema, pero en un marco mayor. Entonces, la idea de hacer un Sin título II no funcionó, lo que hemos hecho es un Sin título revisado, que cada vez que vuelve a escena revisamos en ese marco del paradigma de los derechos humanos.

Discurso de promoción [de 2017] es una mirada más política, en el sentido de decir: "si el informe final de la Comisión de la Verdad dice que esto es un estado sustentable en la exclusión, yo diría que la tesis central de ese informe final, la parte de las cifras terribles que dan ahí de las estadísticas, eso es un estado sustentable de y en exclusión; es un estado que no nos representa”. Yo pensaba que había que poner énfasis ahí. Por eso, empezamos a mirar dónde empieza ese estado. ¿Cuál es el icono de la independencia? El cuadro de Juan Lepiani [es conocido por todos los niños peruanos durante sus clases de colegio]. A partir 
de ahí, problematizar lo que se ve en el cuadro, lo que es la idea de peruanidad, camino al Bicentenario de la Independencia, porque, en el 2021, Perú celebra 200 años de República y todo el estado está planteando cómo van a hacer esa fiesta, esa celebración y la pregunta para nosotros es: “¿qué tenemos que celebrar?”. La corrupción en este país es terrible, lo estamos viendo. Yo creo que ese Discurso de promoción ya sale del paradigma anterior y te pone un plan más bien del carácter del estado, y es una mirada más política del punto de vista de cómo Yuyachkani ve políticamente al Perú en el mundo.

Esa sería la segunda etapa. La tercera es la que estamos empezando. No creo que pueda revelar mucho ahora, pero tiene que ver con cómo, en el último cuarto del siglo, se ha normalizado un pensamiento y se ha instaurado el neoliberalismo. A la manera del fujimorismo, ha generado un comportamiento donde la vida cotidiana y nosotros tenemos ya normalizada una serie de maneras de entendernos como peruanos, en lo cultural, económico, político, en las leyes, en la violencia de género. Y el tema de la memoria es un punto importante en esta parte, pero ya no es la obsesión, ya no es solamente el tema de la memoria lo que nos mueve: es un marco mucho mayor. En ésas estamos. La idea es que eso sea como un cuadro con tres maneras de entrar.

AF: ¡Muchas gracias, Miguel!

PL: Muchas gracias por ser una inspiración para que nuestros imaginarios sigan creando formas de resistir y sobrevivir.

MR: Gracias a ustedes por esta visita y por estar presentes siempre. Ha sido muy enriquecedor hablar y compartir este viaje hacia para mí, para empezar a recordar. 